\title{
Building an Economical and Sustainable Lunar Infrastructure to Enable Lunar Industrialization
}

\author{
Dr. Allison F. Zuniga ${ }^{\mathrm{i}}$, Mark Turner ${ }^{\mathrm{ii}}$ and Dr. Daniel Rasky ${ }^{\mathrm{iii}}$ \\ NASA Ames Research Center, Moffett Field, CA 94035 \\ and \\ Mike Loucks $^{\mathrm{iv}}$, John Carrico ${ }^{\mathrm{v}}$ and Lisa Policastri ${ }^{\mathrm{vi}}$ \\ Space Exploration Engineering Corp, Friday Harbor, WA 98250
}

\begin{abstract}
A new concept study was initiated to examine the architecture needed to gradually develop an economical, evolvable and sustainable lunar infrastructure using a public/private partnerships approach. This approach would establish partnership agreements between NASA and industry teams to develop a lunar infrastructure system that would be mutually beneficial. This approach would also require NASA and its industry partners to share costs in the development phase and then transfer operation of these infrastructure services back to its industry owners in the execution phase. These infrastructure services may include but are not limited to the following: lunar cargo transportation, power stations, communication towers and satellites, autonomous rover operations, landing pads and resource extraction operations. The public/private partnerships approach used in this study leveraged best practices from NASA's Commercial Orbital Transportation Services (COTS) program which introduced an innovative and economical approach for partnering with industry to develop commercial cargo services to the International Space Station. This program was planned together with the ISS Commercial Resupply Services (CRS) contracts which was responsible for initiating commercial cargo delivery services to the ISS for the first time. The public/private partnerships approach undertaken in the COTS program proved to be very successful in dramatically reducing development costs for these ISS cargo delivery services as well as substantially reducing operational costs. To continue on this successful path towards installing economical infrastructure services for LEO and beyond, this new study, named Lunar COTS (Commercial Operations and Transport Services), was conducted to examine extending the NASA COTS model to cis-lunar space and the lunar surface. The goals of the Lunar COTS concept are to: 1) develop and demonstrate affordable and commercial cis-lunar and surface capabilities, such as lunar cargo delivery and surface power generation, in partnership with industry; 2) incentivize industry to establish economical and sustainable lunar infrastructure services to support NASA missions and initiate lunar commerce; and 3) encourage creation of new space markets for economic growth and benefit. A phased-development approach was also studied to allow for incremental development and demonstration of capabilities needed to build a lunar infrastructure. This paper will describe the Lunar COTS concept goals, objectives and approach for building an economical and sustainable lunar infrastructure. It will also describe the technical challenges and advantages of developing and operating each infrastructure element. It will also describe the potential benefits and progress that can be accomplished in the initial phase of this Lunar COTS approach. Finally, the paper will also look forward to the potential of a robust lunar industrialization environment and its potential effect on the next 50 years of space exploration.
\end{abstract}

${ }^{\mathrm{i}}$ Project Development Manager, Ames Space Portal Office and AIAA Associate Fellow

${ }^{i i}$ Senior Systems Engineer, Engineering Directorate and AIAA Senior Member

iii Senior Scientist, Ames Space Portal Office, and AIAA Associate Fellow

${ }^{\text {iv }}$ CEO, Astrogation/Applied Physics, Friday Harbor, WA and AIAA Member

$\checkmark$ CTO, Technical Advisor, Friday Harbor, WA and AIAA Senior Member

${ }^{v i} \mathrm{COO}$, Principal Aerospace Engineer, Friday Harbor, WA and AIAA Senior Member

1

American Institute of Aeronautics and Astronautics 


\section{Nomenclature}

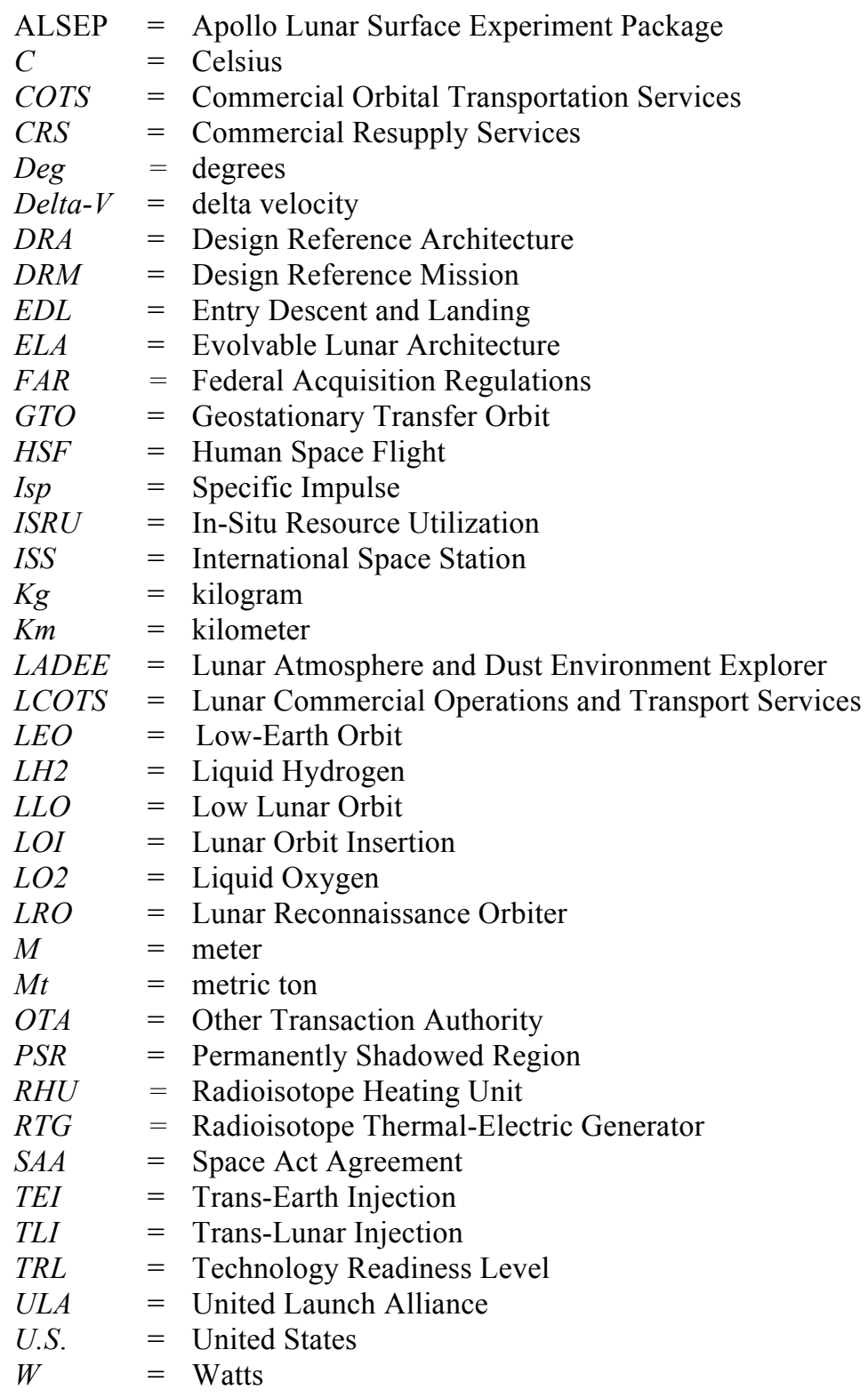

\section{Introduction}

T ESSONS learned from history reveal that government can play an essential role in opening new frontiers for economic growth and industrial development. More specifically, there are a number of examples from past history that illustrate the significant role that government has played in investing in infrastructure to spark economic growth in new frontiers. For example, in the late $15^{\text {th }}$ century, the Spanish government funded Christopher Columbus to search for new trade routes to Asia for economic growth. Although it's famously known that Columbus never reached Asia, he discovered the New World instead. The Spanish government quickly took advantage of this new discovery and established permanent trans-atlantic and trans-pacific trade routes to transport a wide variety of exports ranging from agricultural goods to silver, gold and other exotic goods. Spain also invested in infrastructure to establish colonies and grow agricultural products. As a result, Spain soon became the first European power to settle and colonize large areas from North America to the southern tip of South America. In addition, as a result of all their investments, Spain became the richest country in Europe by the end of the $16^{\text {th }}$ century.

Another good example of government investments for promoting economic development is the opening of the U.S. Western frontier. The first major investment was the Louisiana purchase in 1803 which doubled the size of the 
U.S. at the time. Thomas Jefferson made this purchase from the French because he believed it would create millions of new farms and expand economic opportunities in the new frontier. Jefferson also funded the Lewis and Clark expedition to explore and establish new trade routes from St. Louis to the Pacific coast. The expedition was successful in mapping out the regions and opening up new trade routes that incentivized entrepreneurs to establish new fur trading and other lucrative businesses. The government also invested in technology to improve its water transportation and navigation systems through the Ohio, Mississippi and Missouri rivers which also helped to open up trade routes. In the 1860's, Congress enacted the Pacific Railroad acts to construct the first transcontinental railroad to link railways from New York to California. The line was completed in 1869 which shortened travel to 8 days instead of 6 to 10 month long wagon train expeditions. The government also encouraged settlers during this time to buy railroad land with promotional loans that were affordable to the settlers. All these government investments and incentives for infrastructure development and industrial growth in the Western frontier had great returns of investment. It resulted in making the U.S. the largest economy in the world which still stands today at approximately $\$ 18$ trillion representing a quarter share of the global economy.

It is also very important to study examples from past history that were not successful in economic growth and development to compare and contrast with successful outcomes. This review of examples should help understand the key elements for creating a successful new economy in a remote and hostile environment, such as the Moon. One good example is Antarctica in the South Pole. Antarctica provides a clear example on how to minimize and prevent private investment and ultimately discourage economic development. McMurdo Station in Antarctica was developed by the U.S. government for the sole purpose of pure science and environmental protection. In 1982, the National Science Foundation was given primary responsibility for managing and funding the U.S. Antarctica Program. There are many similarities between Antarctica and the Moon since both are remote and hostile environments. Also Antarctica's legal status is similar to that of the Moon since no nation can claim its land as specified under an international treaty, similar to the Outer Space Treaty of 1968. ${ }^{1}$ Lessons learned from Antarctica as cited by Miller ${ }^{2}$ listed the following main reasons that resulted in no significant economic development in Antarctica. These lessons learned included:

1) There were no policy requirements to stimulate commercial activity at the South Pole. Their sole mission was focused on science.

2) Mining in Antarctica was explicitly prohibited by the 1991 Madrid Protocol to the Antarctic Treaty.

3) There was no strong incentive to allow the infrastructure services to be competed within industry. As a result, most of the infrastructure services were provided by the DOD.

4) The entire culture and value system of the international Antarctica community is aligned to discourage and prevent private investment in developing facilities, infrastructure and resources in Antarctica.

If the Moon is developed under these same guidelines which focuses its development primarily on science and environmental protection, it will more than likely have the same outcome as Antarctica with very little economic growth. By comparing this outcome to the previous examples where economic growth exploded in these new regions of the Americas, it is clear that strategic government planning can be instrumental to promoting new economic growth and development. Therefore, if creating a space-based economy is an important goal of future lunar exploration, it is critical that economic development be encouraged through government incentives, policy, partnerships and investments to stimulate commercial activity on the lunar surface.

\section{Lunar COTS Concept}

Earlier versions of the Lunar Commercial Operations and Transport Services (LCOTS) concept was previously outlined by Zuniga ${ }^{3}$, et al. This concept has been evolving as more studies and analyses are performed with the common goal of achieving an industrialized lunar surface and healthy space-based economy to benefit NASA, U.S. industry and the international space community. The Lunar COTS concept was based on the unique acquisition model from NASA Johnson Space Center's COTS program entitled, Commercial Orbital Transportation Services. ${ }^{5}$ This program was very successful in developing and demonstrating cargo delivery capabilities to the ISS in partnership with industry. It was planned together with the ISS Commercial Resupply Services (CRS) contracts which awarded SpaceX and Orbital Sciences Corp. (now known as Orbital ATK) in 2008 to resupply the ISS on a regular basis with unpressurized and pressurized cargo. As a result of the COTS and CRS programs, 2 new launch vehicles and spacecraft were developed and have been successfully servicing the ISS program since 2012 with cargo transportation missions: 1) SpaceX's Falcon 9 launch vehicle and Dragon spacecraft; and 2) Orbital's Antares launch vehicle and Cygnus spacecraft. Recent studies have shown that government funding investments provided less than one half of the cost for these two commercial transportation systems ${ }^{5}$ ( $47 \%$ government funding for SpaceX and 42\% government funding for Orbital). Also, it has been estimated that the final development cost for 
SpaceX's Falcon 9 rocket was about $\$ 400 \mathrm{M}$ which is approximately 10 times less than projected costs of approximately $\$ 4 \mathrm{~B}$ for the same rocket using traditional cost-plus contracting methods. ${ }^{6}$

Another extension of COTS is NASA's Commercial Crew Program which was originally planned as an option in the original COTS solicitation of 2006. This program has been making significant progress in reaching its goal of achieving safe, reliable and cost-effective commercial human transportation services to ISS and LEO in partnership with industry. In September 2014, the Commercial Crew Program awarded two industry teams, SpaceX and Boeing, to develop a human space transportation capability for eventual launch of astronauts to the ISS. Presently, these industry partners are making significant progress and nearing the final stages of development of their human space transportation systems. Both Boeing and SpaceX are scheduled to flight test their systems with crew in mid-2018. This accomplishment would mark the first time in history that an entirely commercial space transportation system will deliver crew into low-earth orbit (LEO). From the early planning of COTS/CRS programs to today's routine commercial cargo delivery services to tomorrow's commercial human transportation flights to LEO, these programs have truly revolutionized the aerospace industry by expanding the commercial space markets in LEO and lowering the space transportation costs for the entire world market.

The key to the huge success of the COTS program can be primarily attributed to its unique acquisition model which was developed in 2005 together with the program plan. At the time, it was desired to enter into partnership agreements with industry teams to develop new space transportation capabilities and services where both parties had 'skin in the game' in terms of both cost and risk. It was also important to incentivize industry to capture new commercial markets and not solely rely on NASA as the customer. For this new acquisition method, NASA's Other Transaction Authority (OTA) under the Space Act was examined to create a mechanism to invest resources into the industry partner for development of these commercial capabilities for mutual benefit. As a result, the COTS program office elected to use Funded Space Act Agreements ${ }^{7}$ (FSAAs) in their acquisition strategy prior to releasing their solicitation in 2006. The FSAAs were structured to allow much more flexibility to the industry partner with less insight and oversight from NASA, allowing for innovation without being encumbered with the full administrative and reporting requirements traditionally required by FAR contracts. However, this approach also offered more risk which has been addressed by NASA Policy directives, Space Act Agreements Guide ${ }^{8}$ and Space Act Agreements Best Practices Guide. ${ }^{9}$ Highlights of these best practices that were used under the COTS acquisition approach are listed below:

1) NASA and commercial partners share cost, development and operational risk to demonstrate new capabilities and services for mutual benefit.

2) NASA makes long-term commitments to procure commercial services to help secure private investments.

3) NASA encourages commercial partners to target space markets outside Government to make their business case close. NASA is anchor customer but not sole customer.

4) NASA uses $\boldsymbol{F S A A}$ 's to enter into partnership with commercial partners to offer maximum flexibility in design solutions without the full demands and requirements of typical FAR-based contracts.

5) NASA includes pay-on-performance milestones in FSAA's to provide several off-ramps and reduce programmatic risk.

6) Commercial partners retain Intellectual Property (IP) rights and operates and owns its final product(s).

As was previously discussed, this new acquisition approach or model was used as the basis for the Lunar COTS conceptual study. The goal for this study was to develop a plan based on the COTS model to partner with industry to develop new capabilities for cis-lunar space and the lunar surface for mutual benefit as well as to stimulate new commercial markets to grow a new space-based economy. Toward this end, development of lunar infrastructure systems was studied and analyzed to benefit both NASA and its commercial space partners. The benefits to NASA would be shared development costs and new, affordable products and services to accomplish its science and exploration missions. The benefits to industry would be shared technical expertise as well as shared development costs to help raise private capital, implement new business plans and lower risk to capture new lunar markets, such as lunar mining and lunar tourism, in a new frontier.

As a result of this study, the specific goals for the Lunar COTS concept were defined and are listed here:

1) Develop and demonstrate affordable and commercial cis-lunar and surface capabilities, in partnership with industry;

2) Incentivize industry to establish economical and sustainable lunar infrastructure services to support NASA missions and initiate Lunar Commerce;

3) Encourage creation of new space markets for economic growth and benefit.

4

American Institute of Aeronautics and Astronautics 
These goals were slightly updated from the goals listed in reference 4 to reflect the new direction of developing lunar infrastructure capabilities that could benefit both NASA and its industry partners. The Lunar COTS plan also included a three-phase approach for new campaigns of low-cost, commercial-enabled missions which allow for incremental development and demonstration of cis-lunar and surface capabilities and services as shown in Table 1. Note that Phases 2 and 3 focus on infrastructure services to enable resource extraction and lunar mining after Phase 1 is completed. This phased-development and implementation plan is a lower-risk approach since it allows for several off-ramps at the end of each phase. The time in between phases and missions also allows for updates to the goals and objectives for each subsequent phase based on examination of the ground truth gathered in the previous phase. For example, resource extraction and other mission objectives will be better defined depending on the accessibility and economic viability findings of the first phase. Therefore, the goals and objectives of Phase 2 and 3 are fairly generic now but are expected to be better defined as missions are accomplished. The following table summarizes the tentative goals presently defined for each phase.

\section{Table 1. Three-Phase Approach to Lunar COTS Concept}

\begin{tabular}{|c|c|c|}
\hline $\begin{array}{c}\text { Phase 1: Low-Cost, Commercial- } \\
\text { Enabled Missions }\end{array}$ & $\begin{array}{l}\text { Phase 2: Pilot Scale } \\
\text { Demonstration }\end{array}$ & Phase 3: Long-Term Contracts \\
\hline $\begin{array}{l}\text { Partner with industry to develop } \\
\text { capabilities to enable an evolvable } \\
\text { lunar infrastructure; } \\
\text { - Includes lunar cargo delivery, } \\
\text { power stations, communication } \\
\text { towers, etc. } \\
\text { - Assess potential lunar sites for } \\
\text { accessibility to lunar resources and } \\
\text { economic build-up of lunar } \\
\text { infrastructure. }\end{array}$ & $\begin{array}{l}\text { Demonstrate infrastructure } \\
\text { services on a pilot-scale to support } \\
\text { future NASA missions and lunar } \\
\text { commercial activities, such as, } \\
\text { lunar mining or resource } \\
\text { extraction. } \\
\text { Evaluate feasibility and economics } \\
\text { of scaling up production to full } \\
\text { scale. }\end{array}$ & $\begin{array}{l}\text { - NASA awards long-term contracts } \\
\text { for infrastructure services, such as, } \\
\text { lunar cargo delivery and } \\
\text { power/comm services. } \\
\text { - NASA may also award long-term } \\
\text { contracts for full-scale resource } \\
\text { production and/or delivery to cis- } \\
\text { lunar destinations. }\end{array}$ \\
\hline
\end{tabular}

Phase 1 objectives are currently focused on developing capabilities in partnership with industry to enable a commercial and economical lunar infrastructure. As was mentioned in the Introduction section, historically, government can play a key role in promoting and initiating economic growth in a new territory or frontier by investing in infrastructure development and incentivizing industry to create new businesses to stimulate commercial activity. To promote and initiate lunar commerce, several lunar infrastructure elements should be developed and placed into service to help lower the barriers of entry to commercial space companies. These lunar infrastructure elements can range from lunar cargo transportation to power and communication services to autonomous surface operations depending on the lunar commercial activity of interest, such as lunar mining or lunar tourism. However, there are some basic elements that are common to all potential lunar commercial activity as well as future NASA surface missions. These basic, common elements were determined to include lunar cargo delivery, power generation and storage, communications, navigation, thermal control and surface mobility systems. Therefore, this Lunar COTS study focused on development and conceptual design of these basic elements. Toward this end, a reference architecture was defined to evaluate performance, cost, risks including technical and environmental challenges to be overcome to successfully implement an infrastructure system consisting of these basic elements. The following sections will describe this reference architecture, concept of operations and the initial findings from this study.

\section{Lunar Infrastructure Elements}

A review of lunar infrastructure elements was performed to determine basic, common infrastructure elements that may benefit both NASA and commercial space company interests. As previously mentioned, it was determined that near-term infrastructure development should focus on lunar cargo delivery, power generation and storage, communications, navigation, thermal control and surface mobility systems to augment the capabilities of future surface missions without adding significant cost and mass to the original mission. Presently, lunar surface missions are heavily constrained by mass, volume, power availability, battery life, direct line-of-sight communications to 
Earth, extreme thermal conditions, landing conditions, traverse distances, rough and steep terrain. In addition, the Moon sees approximately 14.77 days of sunlight followed by 14.77 days of darkness due to its synodic period of approximately 29.5 days. This approximate 14 day/night cycle presents difficult engineering challenges since the daylight temperatures can reach $127 \mathrm{deg}$ Celsius and night-time temperatures can reach $-173 \mathrm{deg} \mathrm{C}$ at the equator. Surface temperatures at the poles are even colder reaching approximately $-258 \mathrm{deg} \mathrm{C}$ due to the very low incidence angle of the sunlight ${ }^{10}$. Most electronics and spacecraft subsystems, such as batteries, transponders and solar panels will freeze and die at these extreme temperatures. Therefore, lunar surface missions must be designed with radiators and other passive cooling systems to keep subsystems from overheating during the daylight while also be designed with sufficient power to operate heaters during the 14-day lunar night to keep subsystems within acceptable temperature limits.

To date, there have been 20 successfully controlled soft landings on the lunar surface as illustrated in Figure 1. There have been several other hard or crash landings on the lunar surface (not shown in the figure) which have intentionally or unintentionally impacted the lunar surface. As shown in figure 1, the Soviet Union's Luna ${ }^{11}$ missions successfully landed spacecraft on the lunar surface eight times including Luna 9 which was the first probe ever to achieve a soft landing on another solar system body in Feb 1966. These missions were designed as orbiters and landers with 15 successful missions overall extending between 1959-76. The objectives of these missions were to take images of the surface and perform many experiments, studying the Moon's chemical composition, gravity, temperature and radiation. Other notable achievements among the missions that successfully landed on the Moon include sample return missions successfully performed on Luna 16, 20 and 24. Also Luna 17 and 21 were the first missions to deploy remote-controlled roving vehicles, Lunokhod 1 and 2, on the lunar surface.

In the same period of time of these Luna missions, NASA also performed a campaign of pre-cursor robotic missions, named Surveyor ${ }^{12}$, between 1966-68. These missions were sent to the lunar surface in preparation for the Apollo manned missions. The primary goal of these missions was to demonstrate soft landings and evaluate the suitability of landing sites. In total, there were 7 missions launched to the lunar surface but only 5 spacecraft landed successfully. These 5 stationary spacecraft successfully collected thousands of images and scientific data in 4 separate mare sites in the Moon's equatorial belt which were being considered for Apollo manned lunar landings. The fifth mission investigated a region deep within the southern highlands near the Tycho crater. These missions were followed by the 6 historic Apollo manned lunar missions from 1969-1972 also shown in Figure 1.

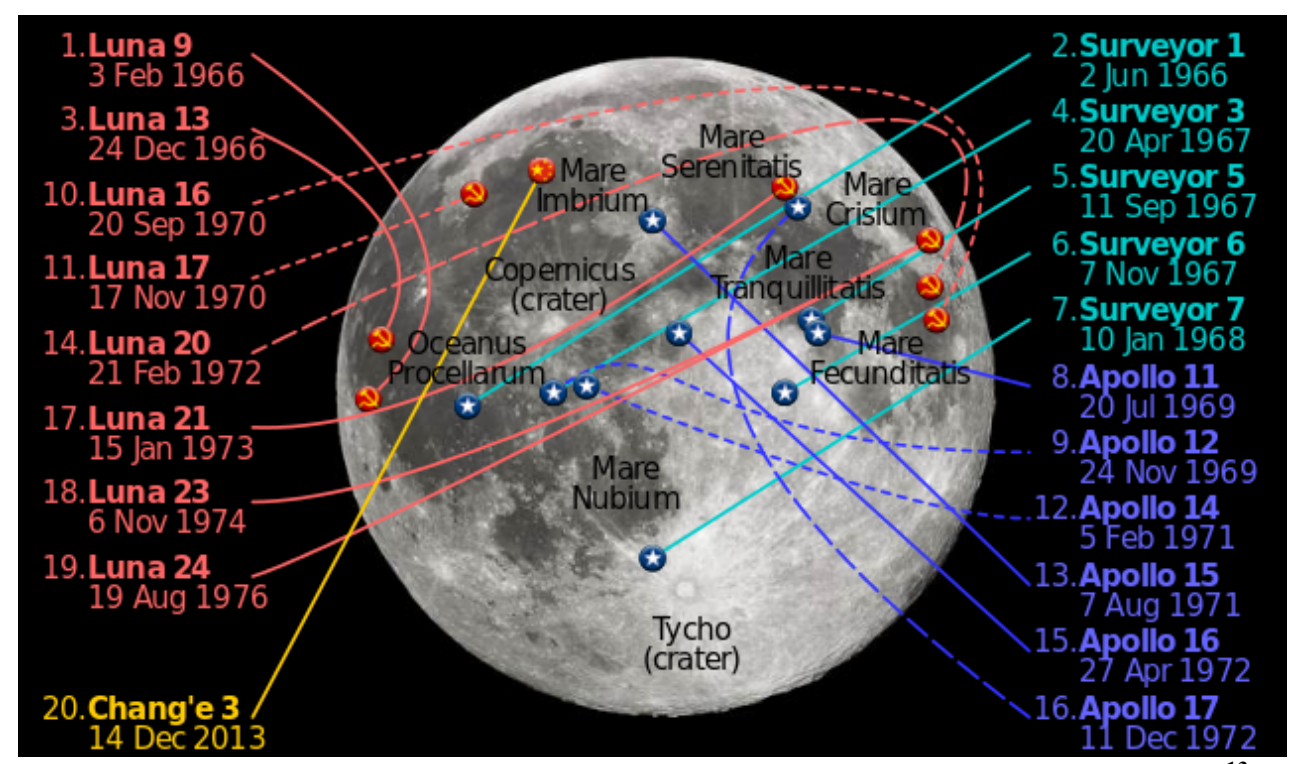

Figure 1. List of All Successful Soft Landings to the Lunar Surface by Freiman ${ }^{13}$ 
Table 1. List of All Lunar Surface Missions That Have Survived one or more 14-day Lunar Nights

\begin{tabular}{|l|l|l|l|c|}
\hline Lunar Mission & Lunar Landing & Last Contact & $\begin{array}{l}\text { Surface Mission } \\
\text { Duration }\end{array}$ & $\begin{array}{l}\text { Landed Mass and } \\
\text { Distance traveled }\end{array}$ \\
\hline Surveyor 1 & Jun 2, 1966 & Jan 7, 1967 & 7 months & $292 \mathrm{~kg}$ \\
\hline Surveyor 5 & Sep 11, 1967 & Dec 17, 1967 & 3 months & $303 \mathrm{~kg}$ \\
\hline Surveyor 6 & Nov 7, 1967 & Dec 14, 1967 & 6 weeks & $300 \mathrm{~kg}$ \\
\hline Surveyor 7 & Jan 10, 1968 & Feb 21, 1968 & 7 weeks & $306 \mathrm{~kg}$ \\
\hline Luna 17 or Lunokhod 1 & Nov 17, 1970 & Oct 4, 1971 & 10 months & $756 \mathrm{~kg}(\mathrm{rover}) / 10.5 \mathrm{~km}$ \\
\hline Luna 21 or Lunokhod 2 & Jan 15, 1973 & May 11,1973 & 4 months & $840 \mathrm{~kg}(\mathrm{rover}) / 39 \mathrm{~km}$ \\
\hline Chang'e 3 and Yutu rover & Dec 14,2013 & Aug 3,2016 & 31 months & $140 \mathrm{~kg}(\mathrm{rover})$ \\
\hline
\end{tabular}

Most of all the surface missions shown in Figure 1 lasted less than one lunar day (or 14 Earth days) of surface operations including the Apollo missions which ranged from 1 to 3 days. However, 7 of those 20 missions did survive one or more 14-day lunar nights as listed in Table 1. These missions included 4 Surveyor missions that operated for one or more lunar nights by hibernating through the extremely cold lunar nights. The stationary Surveyors were powered by a 0.85 square meter array of solar cells that were mounted on top of its mast. This solar array generated up to $85 \mathrm{~W}$ of power which was stored in rechargeable silver-zinc batteries. ${ }^{14}$ There were 2 compartments that were thermally controlled using superinsulating blankets, conductive heat paths, thermal switches and small electric heaters mounted on the spacecraft structure. One compartment held temperatures between 5 and $50 \mathrm{deg} \mathrm{C}$ for the communications and power supply electronics. The other temperatures held temperatures between 20 and $50 \mathrm{deg} \mathrm{C}$, for the command and signal processing components.

There were also 2 Lunokhod $^{15}$ rovers which operated successfully on the lunar surface for several lunar nights and traveled distances up to $39 \mathrm{~km}$. The Lunokhod rovers were powered by batteries providing approximately 180 $\mathrm{W}$ of power. These batteries were recharged during the lunar day by its solar cell array. During the lunar nights, the rovers hibernated and were heated by a polonium-210 radioisotope heater unit (RHU) which maintained the internal subsystems above freezing temperatures. These rovers were much larger and massive than the Surveyor missions which resulted in much longer surface operations. However, Lunokhod 2 ended earlier than planned after 4 months of operation due to lunar dust from a crater wall falling over the radiators. As a result, the rover was unable to cool itself and its internal temperature climbed excessively, eventually rendering the rover inoperable.

After the Soviet Union's Luna 24 mission in August 1976, there were no more surface missions until China's Chang'e 3 mission landed successfully on December 14, 2013 which was 37 years later. The Chang'e 3 mission successfully delivered the lunar rover, Yutu ${ }^{16}$, to Mare Imbrium. The rover was designed to explore an area of 3 square $\mathrm{km}$ with a maximum traveling distance of $10 \mathrm{~km}$. The stationary lander was equipped with an RHU in order to heat its subsystems and power its operations, along with its solar panels, during its planned one-year mission. The Yutu rover was powered by 2 solar panels during the lunar day and was placed in sleep mode during the lunar night. It was also heated with an RHU using plutonium-238. During the second lunar day, the rover experienced a mechanical control abnormality and a control circuit malfunction in its driving unit which prevented it from entering normal dormancy. As a result, the rover was unable to move and serious technical troubles persisted that hampered science operations. However, the rover was still able to transmit data every lunar day until August 3, 2016 when the rover ceased all operations.

In addition to the surface missions listed in Table 1, there were 5 experiment packages named Apollo Lunar Surface Experiment Package ${ }^{17}$ (ALSEP), that were delivered by the astronauts of Apollo missions 12, 14, 15, 16 and 17. The ALSEP consisted of a set of scientific instruments for long term study of the lunar environment designed to run autonomously after the astronauts departed. They were powered by a Radioisotope Thermoelectric Generator (RTG). These units utilized the heat from radioactive decay of plutonium-238 and thermocouples to generate approximately $70 \mathrm{~W}$ of power. These packages were controlled from the ground and operated from deployment until September 30, 1977 when they were turned off for budgetary reasons. Additionally, by 1977 the power packs could not run both the transmitter and any other instrument due to the significant reduction in power.

Except for the Surveyor missions, all of these surface missions used radioactive power sources to provide sufficient long-term power and heat to maintain its subsystems above freezing temperatures through several lunar nights. These RHUs and RTGs are small devices that provide heat through radioactive decay of a radioactive isotope, such as plutonium or polonium. Although these units provide good thermal performance for many years, they severely add cost and complexity to its deep space missions. Since radioactive sources are very scarce, these 
units are very expensive and difficult to acquire and procure. These units are also heavily regulated by the Department of Energy making them very difficult to handle and adding significant risk to the mission due to all the safety concerns. Consequently, these RHUs and RTGs are highly undesirable for low-cost commercial missions. Therefore, our reference architecture for the lunar infrastructure system focused on power stations based solely on solar power and batteries to maintain an economical approach to infrastructure development.

\section{A. Reference Lunar Architecture}

A reference lunar architecture was developed to carefully examine the design space and evaluate the performance and technical challenges of each basic element for a lunar infrastructure system. These basic elements consisted of the following: lunar lander, power station, communication tower, navigation, thermal control and surface mobility or rover systems. The reference architecture along with its basic elements are illustrated in Figures 2 through 4.

The basic elements were conceptually designed to provide multiple functions. The lunar lander, as illustrated in figure 2, provides soft, precision landings at desired destinations for any latitude or longitude on the lunar surface. The power station, as illustrated in figure 3, was designed to provide power generation and energy storage capabilities. This power station also has the capability to recharge small rovers and other payloads as shown in figure 4. The communication tower, as illustrated in figure 3, provides communication links between the rover systems, power station and Earth ground stations. The navigation system located on the top of the communication tower consists of a landing beacon and other navigational aids. These navigation aids triangulated with other communication towers can serve to aid other lunar landers in their final approach to precisely reach its landing destination. It can also provide navigational assistance to autonomous rovers as they navigate through dark areas, such as craters and caves. The thermal control system provides sufficient heating to the rovers and other subsystems to survive the extremely cold conditions during the 14-day lunar nights as shown in figure 4. The small rover systems shown in figure 4 have the capability to operate autonomously with commands from the ground, carry science instruments and other small payloads, acquire measurements and transmit data back to Earth via the communication tower.

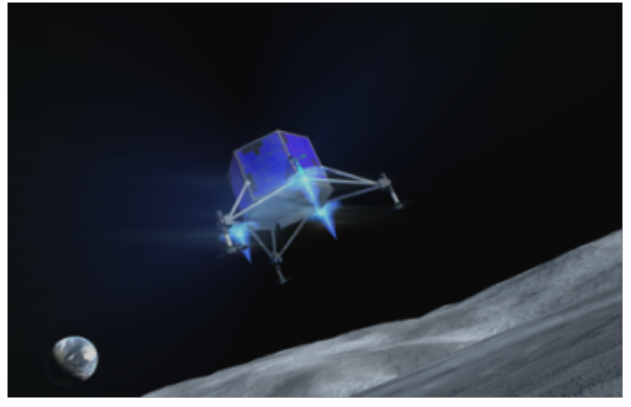

Figure 2. Lunar Lander firing thrusters

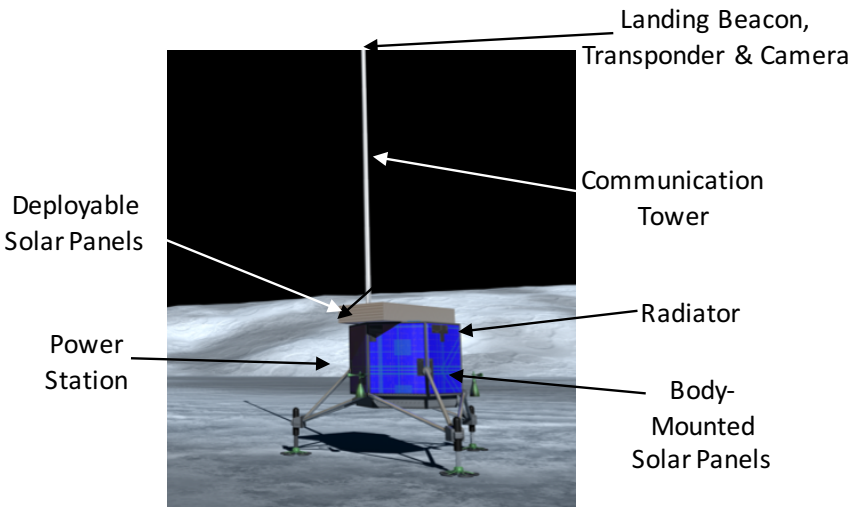

Figure 3. Power Station and Communication Tower

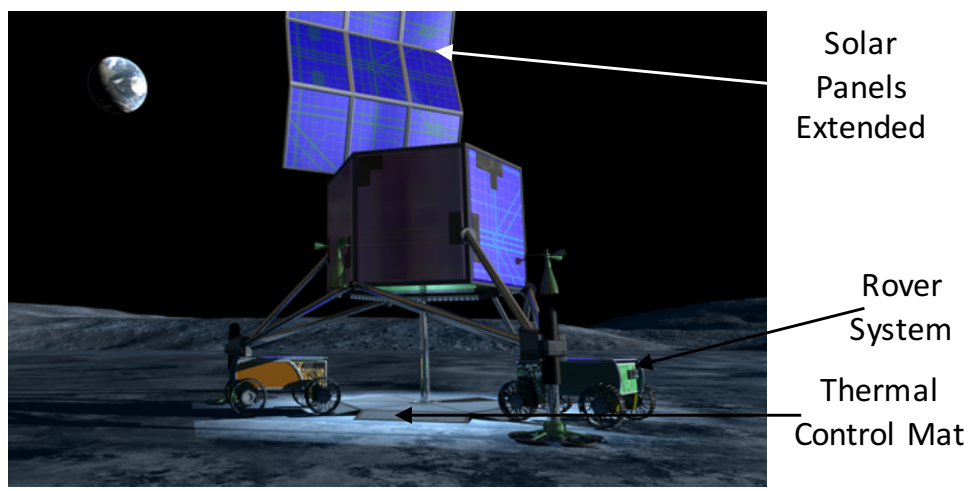

Figure 4. Power Station recharging 2 small rover systems

8

American Institute of Aeronautics and Astronautics 
The lunar lander design is based on a common bus architecture similar to that used for the LADEE spacecraft. ${ }^{18}$ Many of the subsystems such as the avionics and flight controls were based on heritage hardware from LADEE. The design used a 2 meter diameter hexagonal aluminum bus structure with 3 lander legs which can fit within a 4 meter payload fairing. The legs were designed as tripod legs that can self-level after landing as illustrated in figure 3 . The lander design's primary requirements were to: 1) land within 100 meters from a specified landing site; 2) stay within a targeted landed dry mass of 900-1000 kg including payloads; and 3) deliver payloads with mass range of 350-450 $\mathrm{kg}$ to a specified landing site.

The power station design, as illustrated in figure 3, included body-mounted solar panels and deployable solar panels to generate power as well as lithium ion batteries to store power. Preliminary analysis suggests 2 to 4 square meters of surface area should generate approximately 800 to $1600 \mathrm{~W}$ of continuous power during the lunar day. This range of power should be more than adequate to power all the subsystems during normal operations. It was also estimated that approximately 4 square meters of solar panels pointed normal to the sun would charge up to 36 battery modules in approximately 15 hours. In addition, solar panel geometry should be arranged and oriented to be normal to sunlight angle which is dependent on lunar latitude. Therefore, polar landings would require solar panels to be placed in a vertical orientation while equatorial landings would require solar panels be deployed in a horizontal orientation.

As previously mentioned, one of the greatest challenges for operating hardware on the lunar surface has been surviving the lunar night which can reach temperatures of approximately $-258 \mathrm{deg} \mathrm{C}$ at the lunar poles. Also given the difficulty of obtaining a radioactive heating source, the use of batteries to supply keep alive power is highly desirable. An analysis was performed for high TRL lithium ion batteries that were previously flown on the recent LADEE mission. These specific batteries used on LADEE were ABSL Power Solution's lithium ion batteries which has a life expectancy of 6-8 years. ${ }^{19}$ By using 24-36 battery modules of these type batteries, it was estimated that approximately 40-75 Watts of continuous power would be available to run heaters through a 14-day lunar night. It was estimated that this range of power would be more than sufficient for the heaters and other critical components to survive the lunar night since the estimated power consumption used was comparable to both Apollo's ALSEP experiments and Lunokhod power values. It was also estimated that the mass of these 24-36 battery modules is in the range of 150-250 kg which resulted in being the main driver for the payload mass. As a result of this analysis, it was concluded that the power station could endure for 6-8 years with the critical component being the life of the batteries. This added capability will significantly extend the life of future surface missions over previous lunar surface missions as shown in Table 1.

The design also included a telescopic 8-10 meter communication tower that was fitted on top of the power station as shown in figure 3. It is expected that an S-Band or X-band transponder would be placed at the top of the $10 \mathrm{~m}$ tower. This communication system would provide communication links between rover systems up to $500 \mathrm{~m}$ away and Earth ground stations that are in direct line-of-sight of the communication tower. The communication tower would also allow for rovers to communicate between each other. These capabilities would reduce the constraints on the rover systems from solely operating within direct line-of-sight of Earth as it would be capable now of operating within craters and caves as long as it is within line-of-sight of the communication tower. Future plans to add a mobility system to the power station would further expand the operational envelope of rover systems.

The rover systems were provided a mass allocation of $50 \mathrm{~kg}$ each. There is sufficient mass for 2 rovers to be delivered on each lunar lander. The rovers would be dropped down through a cable system after landing. This cable system was a preferable design instead of adding mechanical ramps to the system. The rovers are illustrated in figure 4. A specific design for the rover system was not created as it was out of scope for this study and not a driver for the infrastructure system. However, the functions of the rover were specified and included the following: 1) the rovers will be capable of docking with the power station using inductive charging to fully re-charge its battery supply; 2) the rovers will be put in sleep mode when hibernating through the lunar night and will be docked with the power station for power and to maintain its temperatures within acceptable limits; 3 ) the rovers will be capable of capturing and transmitting images back to the power station; and 4) the rovers will be able to transmit and receive data with the power station and ground Earth stations via the communication tower for distances up to $500 \mathrm{~m}$. Although this final capability limits the travel distances of the rovers to $500 \mathrm{~m}$, further distances may be possible if the rovers were equipped with enhanced navigation autonomy or if the power station is made to be mobile as previously mentioned.

Additionally, each rover was designed to carry science or other payloads with a mass up to $10 \mathrm{~kg}$. There are a number of science instruments that may fit within these mass constraints. Table 2 below lists the potential instruments that may be carried on these small rovers to take specific measurements. It is envisioned that the rovers can be used for resource prospecting using onboard mass spectrometers, measuring radiation levels in lava tubes, or working in conjunction with lunar ice penetrators to relay results back to a nearby lander. Further investigation is warranted to fully flush out all the interface requirements, capabilities and constraints for these science instruments.

9

American Institute of Aeronautics and Astronautics 
Table 2. List of Potential Science Instruments

\begin{tabular}{|l|l|}
\hline \multicolumn{1}{|c|}{ Potential Instrument Options } & \multicolumn{1}{c|}{ Key Measurements } \\
\hline Neutron Spectrometer System & $\begin{array}{l}\text { Senses hydrogen-bearing materials (e.g. ice) } \\
\text { in the top meter of regolith. }\end{array}$ \\
\hline $\begin{array}{l}\text { Near-Infrared Volatile Spectrometer System } \\
\text { (NIRVS) }\end{array}$ & $\begin{array}{l}\text { Identifies volatiles, including water form (e.g. } \\
\text { ice bound) in top 20-30 cm of regolith. Also } \\
\text { provides surface temperatures at scales of } \\
<10 \mathrm{~m} .\end{array}$ \\
\hline Radiation sensors & $\begin{array}{l}\text { Provides high fidelity spectral composition at } \\
\text { range. }\end{array}$ \\
\hline Magnetometer & $\begin{array}{l}\text { Measures radiation shielding by lunar } \\
\text { regolith in lava tubes. }\end{array}$ \\
\hline Seismometer & $\begin{array}{l}\text { Measures variations in the strength of the } \\
\text { Moon's magnetic field }\end{array}$ \\
& $\begin{array}{l}\text { Measures propagation of seismic waves } \\
\text { through the Moon to help understand the } \\
\text { Moon's internal structure. }\end{array}$ \\
\hline
\end{tabular}

\section{Phase I Lunar COTS Concept of Operations}

The Phase I Lunar COTS concept of operations proposes that the reference lunar architecture will launch on a dedicated commercial launch vehicle. Table 3 lists the operational ground rules and assumptions that define the scope for a quantitative analysis.

Table 3. Operational Ground Rules and Assumptions

\begin{tabular}{|l|}
\hline \multicolumn{1}{c|}{ Ground Rules and Assumptions } \\
\hline 1. Launch from a domestic U.S. launch site on a medium-class commercial launch vehicle. \\
\hline 2. The launch vehicle's upper stage will perform Trans-Lunar Injection (TLI) burn. \\
\hline 3. The lunar lander will perform the Lunar Orbit Insertion (LOI) and descent burns. \\
\hline $\begin{array}{l}\text { 4. The lunar lander will deliver payload to specified lunar landing sites at lunar poles and equatorial } \\
\text { locations. }\end{array}$ \\
\hline $\begin{array}{l}\text { 5. The lunar lander will provide power and communications to the payload in transit to the lunar } \\
\text { surface and at the lunar landing site. }\end{array}$ \\
\hline $\begin{array}{l}\text { 6. The lunar lander will provide on-orbit operations during trans-lunar trajectory including } \\
\text { communications to the ground via NASA assets and/or commercial communication architectures. }\end{array}$ \\
\hline $\begin{array}{l}\text { 7. Earth ground stations will maintain communications with lunar lander and payloads, upload } \\
\text { commands and provide communication links to mission control centers. }\end{array}$ \\
\hline $\begin{array}{l}\text { 8. Missions to lunar landing sites at poles or equatorial locations should assume 14 days of maximum } \\
\text { duration of darkness. }\end{array}$ \\
\hline
\end{tabular}

\section{A. Quantitative mission analysis}

To assess the viability of lunar landing missions for current and upcoming commercial launch vehicles, publicly available information for each launch vehicle were obtained to estimate vehicle performance. Because the current market includes geostationary missions, the authors used the published values for the mass delivered to a geostationary transfer orbit, which is similar to a lunar transfer orbit. Understanding that a launch trajectory might be optimized specifically for a lunar transfer, the authors used scale factors ranging from 1.0 to 1.2 that multiplies the mass to a trans-lunar trajectory.

Delta-V values were estimated for a number of trajectories, and then confirmed by running numerical simulations using high-fidelity force models to calculate the delta-V needed for TLI, LOI, and a powered descent and landing on the Moon. The force models included the gravitational effects of the Earth, Moon, and Sun, as well 
as the gravity losses from the LOI capture maneuvers. Similar to previously published work, the runs were made using STK/Astrogator ${ }^{20}$. This commercial software has been used operationally for many missions, including cislunar, lunar, and interplanetary missions ${ }^{21,22,23,24,25,26}$. The delta-V values used for these calculations are shown Table 4 below.

Table 4. Estimated Delta-V Values For Different Maneuvers

\begin{tabular}{|l|c|}
\hline \multicolumn{1}{|c|}{ Maneuver } & Delta-V (meters/second) \\
\hline LEO to GTO & 2,426 \\
\hline TLI (LEO to Lunar Transfer) & 3,105 \\
\hline Lunar Orbit Insertion & 835 \\
\hline Descent and Landing & 1,822 \\
\hline Lunar Mission Total & 8,188 \\
\hline
\end{tabular}

Using the semimajor axes from a Geostationary Transfer Orbit (GTO) approximately 24,396 km to a translunar trajectory of $193,314 \mathrm{~km}$, the difference in delta-V was calculated using the orbital energy conservation equation ${ }^{27}$ or vis-viva equation. The rocket equation ${ }^{28}$ was then used to calculate the mass. Table 5 below shows the Specific Impulse (Isp) used in the rocket equation. The calculations include the total mass delivered to the lunar surface, and an estimate of the useful, non-lander mass defined as the payload mass. The propellant system was estimated at $50 \%$ of the landing propellant mass, and the rest of the lander was estimated to be $1 / 3$ of the landing propellant mass.

Table 5. Estimates of Total Mass and Payload Mass to the Lunar Surface

\begin{tabular}{|l|c|c|c|c|}
\hline \multicolumn{1}{|c|}{ Launch Vehicles* } & $\begin{array}{c}\text { Upper stage } \\
\text { Isp (sec) }\end{array}$ & GTO (mt) & $\begin{array}{c}\text { Total Mass to Lunar } \\
\text { Surface (mt) }\end{array}$ & $\begin{array}{c}\text { Non-lander or Payload } \\
\text { Mass (mt) }\end{array}$ \\
\hline Atlas 551 & 451 & 8.9 & $2.9-4.1$ & $0.57-1.4$ \\
\hline Falcon 9 FT (Full Thrust) & 340 & 8.3 & $2.3-3.2$ & $0.43-1.1$ \\
\hline Falcon Heavy & 340 & 27 & $8.1-11$ & $1.5-3.9$ \\
\hline Vulcan ACES & 448 & 17 & $5.6-7.8$ & $1.1-2.7$ \\
\hline New Glenn 2-stage vehicle & 368 & 13 & $4.2-5.8$ & $0.78-2.0$ \\
\hline
\end{tabular}

*Launch vehicle data obtained from publicly available websites and reports.

Because the GTO values were estimates for each launch vehicle, the authors used a range of inputs to get a range of outputs, including the altitude of the Earth parking orbit, the scale factor for trajectory optimization mentioned earlier, and the Isp of the lander engines. The altitude of the parking orbit had only very small effect, and the optimization scale factor, ranging from 1.0 to 1.2 , only affected the mass by $20 \%$. The largest effect was from the Isp used, which ranged from 285 to $336 \mathrm{sec}$. This range of Isp are typical values for commercial bipropellant engines $\left(\mathrm{MH} / \mathrm{N}_{2} \mathrm{O}_{4}\right)$. As a result, a significant finding of this analysis was that Isp of lunar lander engines are major drivers for the final payload mass capabilities. Therefore, it is recommended that higher Isp engines be included in the lander design for greater performance in landed payload capability.

The authors also varied the landing sites in their trajectory analysis, from equatorial to polar. The resulting differences were less than one percent, and within the uncertainty levels with respect to the inputs. Table 6 lists the four landing sites selected for trajectory runs along with the LOI delta-V and the descent delta-V.

Table 6. Delta-V Variations per Landing Site

\begin{tabular}{|l|c|c|c|c|}
\hline \multicolumn{1}{|c|}{ Landing Site } & Latitude & Longitude & $\begin{array}{c}\text { LOI Delta-V } \\
\text { (meters/second) }\end{array}$ & $\begin{array}{c}\text { Descent Delta-V } \\
\text { (meters/second) }\end{array}$ \\
\hline North Pole & $88.57 \mathrm{~N}$ & $25.73 \mathrm{E}$ & 834.1 & 1812.1 \\
\hline South Pole & $-88.03 \mathrm{~S}$ & $39.85 \mathrm{E}$ & 834.1 & 1811.8 \\
\hline Taurus Littrow & $22.19 \mathrm{~N}$ & $30.77 \mathrm{E}$ & 832.4 & 1823.2 \\
\hline Lacus Mortis & $45.0 \mathrm{~N}$ & $27.2 \mathrm{E}$ & 829.2 & 1824.9 \\
\hline
\end{tabular}




\section{B. Design Reference Missions}

Two Design Reference Missions (DRM) were created for the purpose of developing baseline quantitative estimates of possible missions. Each DRM specified mission objectives to demonstrate capabilities for an evolvable lunar infrastructure that will support future NASA and commercial missions.

The first DRM-1 is illustrated in Figure 5. The launch vehicle is assumed to be of medium class, either SpaceX's Falcon 9 or ULA's Atlas V. From Table 5, the estimated total landed mass delivered by these vehicles ranged from 2.3 to $3.2 \mathrm{mt}$ for Falcon 9 and 2.9 to $4.1 \mathrm{mt}$ for Atlas 551. Given that the targeted dry mass of the lunar lander including payloads ranged between 0.9 to $1 \mathrm{mt}$ as previously stated, it is assumed that these launch vehicles could conservatively deliver between 1 and 2 lunar landers including its payloads on a single mission. It is also assumed that the landers would be stacked on top of each other to stay within the 4 meter payload fairing. This launch capability would allow for multiple landers to target multiple destinations to the lunar surface on a single launch. Upon landing, each lander would deploy its rovers to examine and obtain ground truth data at separate lunar sites.

As shown in figure 5, the upper stage is responsible for providing the TLI burn to place the lander and payload on a direct lunar trajectory to the lunar surface. The lander's descent engines are responsible for providing the LOI burn that will place the lander and payload on a $100 \mathrm{~km}$ low lunar orbit. The lander and payload will orbit the Moon until its final destination is directly below and within sight of the spacecraft. The lander's descent engines will fire and provide a soft landing to the desired destination. A nominal mission timeline for this trajectory is shown in Table 7. The total number of days for launch to lunar landing destination ranges from 7.6 to 14.6 days.

The main objectives for this DRM-1 include the following: 1) demonstrate lunar cargo delivery capabilities to polar and/or equatorial lunar sites; 2) demonstrate power generation and storage capabilities on the lunar surface using solar power battery system; 3 ) demonstrate communication link capabilities from lunar lander and rovers to Earth ground stations via a high-tower communication system; 4) demonstrate continuous operation of power and communication systems including during times of continuous darkness; 5) demonstrate functional use of power station to extend life of the rover by providing recharging capabilities during continuous darkness; and 6) acquire and transmit high resolution images and video of landing site during descent and landing. In addition, there will be specific mission objectives added to the mission based on the science instrument or commercial payload delivered with the infrastructure system.

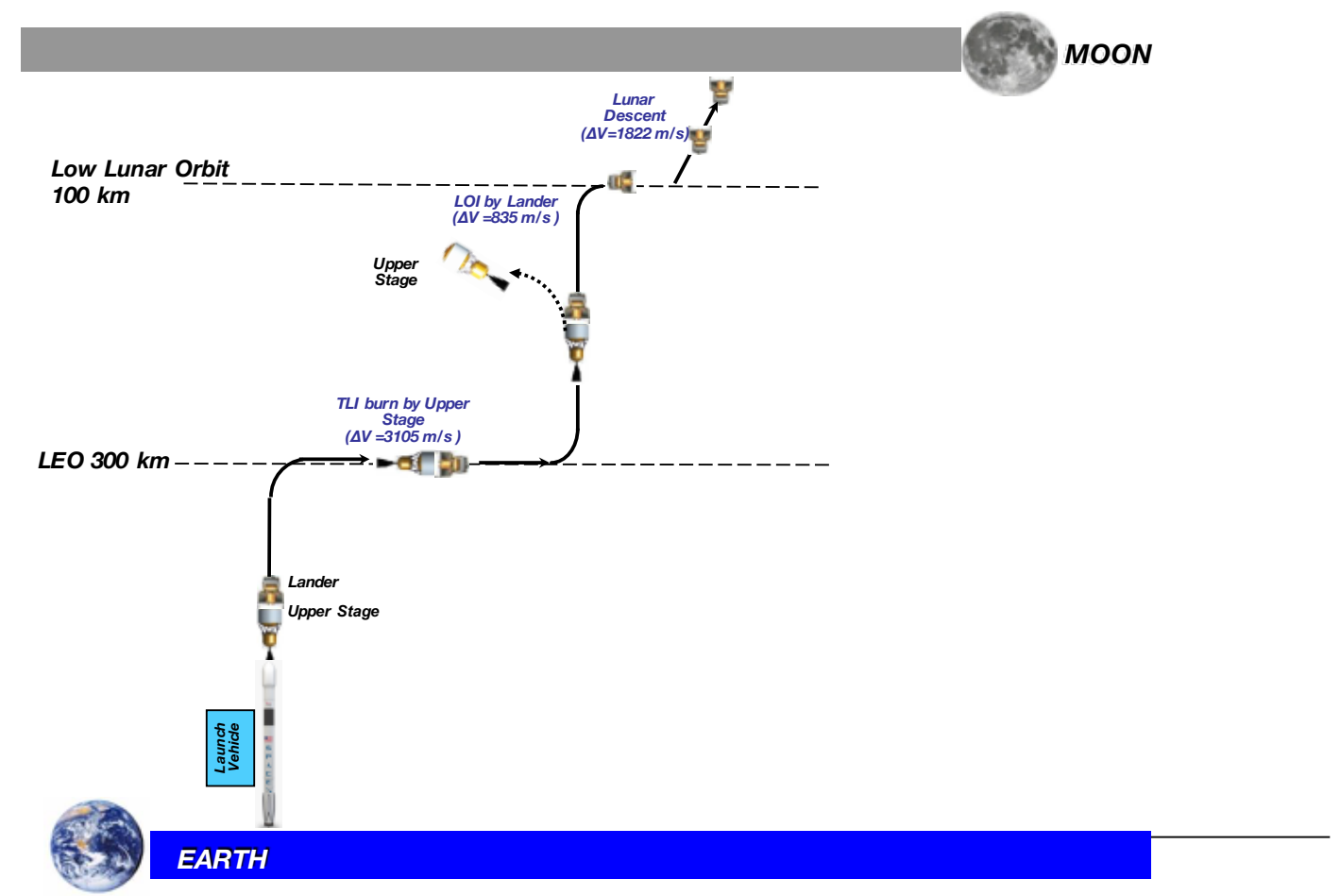

Figure 5. Design Trajectory for DRM-1 
Table 7. Nominal Mission Timeline

\begin{tabular}{|l|c|c|l|}
\hline \multicolumn{1}{|c|}{ Phase } & Min & Max & Units \\
\hline Launch & -15 & -115 & minutes \\
\hline TLI & 0 & 0 & minutes \\
\hline LOI begins & 4.5 & 5.5 & days \\
\hline LOI ends & 6.5 & 7.5 & days \\
\hline Descent Orbital Insertion & 7.5 & 14.5 & days \\
\hline Landing & 7.55 & 14.55 & days \\
\hline
\end{tabular}

The primary objective for DRM-2 is to demonstrate transportation capability to deliver multiple lunar landers (up to 4) to the lunar surface in a single mission. This can be performed with use of a heavy-class launch vehicle, such as, SpaceX's Falcon Heavy, ULA's Vulcan ACES or Blue Origin's New Glenn 2-stage launch vehicle. Table 5 shows that these vehicles provide payload capabilities in the range of 2 to 4 metric tons for a high-performing lunar lander engine. This would provide enough capability to deliver at least 2 lunar landers to the surface. With this added capability, 2 to 4 lunar landers can be launched at once and delivered to multiple sites on the lunar surface. Additionally, this added capability would also allow for larger and heavier lunar landers to be delivered along with larger rovers. Additional study is needed to adequately define the range of size, volume and mass for these larger landers and rovers.

In addition to the objectives of DRM-1, DRM-2 will be able to meet additional objectives including: 1) demonstrate functional use of one or more power stations to extend life of the rovers by providing recharging capabilities for multiple rovers during continuous darkness; 2) demonstrate functional use of one or more communication towers to provide continuous communication links between multiple rovers and Earth ground stations; and 3) demonstrate capability of incoming lunar landers to triangulate data from 3 different communication towers with navigation beacons to aid in their final approach to precisely reach its landing destination.

\section{Enabling Lunar Industrialization}

These Lunar COTS concept missions, as described, will enable development of a new, economical and sustainable lunar infrastructure in partnership with industry. This new infrastructure will have a range of capabilities, as discussed, to provide lunar cargo delivery, power, communications, navigation and autonomous rover operations services. Using the COTS acquisition model, development of these capabilities is planned to take place in partnership with industry to share cost and risk jointly. However, operation of these services will be performed by the industry owners of these capabilities, just as SpaceX took ownership of its launch vehicle assets after completion of its development phase under the COTS program. Additionally, with the incentive of NASA's CRS program to procure cargo transportation services to the ISS, SpaceX was able to continue reducing its operations cost which is approximately $\$ 62 \mathrm{M}$ per launch presently or approximately $\$ 2720 / \mathrm{kg}$ to LEO. This significant reduction in cost has enabled SpaceX to not only capture NASA's procurement contracts for regular cargo delivery services to ISS but also enabled its capture of a significant portion of today's market for satellite launches. This outcome has more than exceeded the expectations of the COTS program when it was initiated back in 2005. Similarly, the Lunar COTS concept is being designed with the expectation that new, affordable and commercial cis-lunar transportation services as well as lunar surface infrastructure services will become operational by the end of its development phase. Although there are many critics that say that a COTS-like program cannot be successful beyond LEO where there are no existing commercial markets, there are substantial companies that are presently investing their own resources to develop new, affordable, deep space capabilities with the expectation that it will create sufficient market demand to grow new markets in cis-lunar space and beyond.

As an example, SpaceX has been developing its Falcon Heavy launch vehicle with internal funding. At 5 million pounds of liftoff thrust, Falcon Heavy will be the most powerful vehicle to reach orbit after the Saturn V. SpaceX plans to use the Falcon Heavy for lunar tourism missions starting next year in 2018. They have already announced their first mission to fly two private citizens on a trajectory around the Moon using their Commercial Crew Dragon that was developed in partnership with NASA under the Commercial Crew Program. By using the Crew Dragon on commercial missions, it will further reduce operational costs for human transportation services for both NASA and commercial missions. Since the beginning of NASA's COTS program, SpaceX has been a strong advocate for this public-private partnership approach and continues to advocate for more COTS-like programs. Recently, SpaceX's senior vice president for global business and government affairs, Tim Hughes, testified in Congress the following, "The principles applied in past programs [such as COTS program] for LEO capability can and should be applied to 
deep space exploration. ${ }^{29}$ " He also encouraged NASA to continue creating more public-private partnership opportunities for deep space with the long-term goal of enabling the U.S. to establish a permanent presence in space.

Another commercial space company with ambitions to operate services in deep space is Jeff Bezos' Blue Origin company. Recently, Bezos has advocated for more public-private partnerships with NASA to build a lunar lander to deliver cargo to the lunar poles of the Moon, where scientists believe there are abundant water-ice resources. Bezos recently stated, "We are hoping to partner with NASA on a program called Blue Moon where we would provide a cargo-delivery service to the surface of the Moon, with the intent over time of building a permanently inhabited human settlement on the Moon. ${ }^{30}$ " Bezos also stated that he was ready to put his own 'skin in the game' and invest his own resources in developing this lunar lander capability. He anticipates a strong market demand for his lunar transportation system once development of a permanently human settlement on the Moon gets underway.

Recently NASA's Lunar Cargo Transportation and Landing by Soft Touchdown (CATALYST) Program sponsored by NASA's Human Exploration and Operations Mission Directorate awarded multiple no-fundsexchanged Space Act Agreements to 3 companies to share NASA's technical expertise with them to aid in their development of lunar transportation capabilities. The overall purpose of the Lunar CATALYST program is to encourage the development of robotic lunar landers that can be integrated with commercial launch vehicles to deliver payloads to the lunar surface. These awarded companies include Astrobotic Technologies of Pittsburgh, PA, Masten Space Systems Inc of Mojave, CA and Moon Express Inc., of Moffett Field, CA. As a result of this program, all 3 companies are currently making significant progress towards developing a commercial lunar lander to provide lunar cargo delivery services to not only NASA but to a broad international community. As an example, Astrobotic's recent press release announced its partnership with United Launch Alliance (ULA) to launch its first mission to the Moon in 2019 using its Peregrine Lander. ${ }^{31}$ According to their plan, this will be the first of many missions to come as Astrobotic strives to become an affordable, routine lunar cargo delivery provider for the broad, international community.

In addition, ULA has been developing their own lunar space transportation concept entitled, Cislunar $1000{ }^{32}$ This concept envisions a self-sustaining, space-based economy that supports 1000 people living and working in cislunar space within the next 30 years. ULA's plan calls for a space transportation system that cycles back and forth between LEO and cis-lunar space powered solely by the resources of the Moon. A major element of this space transportation system is a new upper stage named Advanced Cryogenic Evolved Stage (ACES) ${ }^{33}$ which is a fully reusable and long-duration, in-space stage that can be refueled with LO2 and LH2. Both of these propellants can be created from water-ice resources found on the Moon. Therefore to grow a self-sustaining, space-based economy, ULA's plan involves developing a system that delivers affordable, lunar-based propellant and developing a market demand for this affordable propellant.

All these companies, and many others not cited here, have great interest and ambition to create and grow new space-based markets in cis-lunar space and beyond. These companies are also presently investing their own resources to develop new, affordable deep space capabilities with the expectation that it will spark market demand for these new capabilities and as a result grow new, space-based markets. A COTS-like program, such as Lunar COTS, could definitely accelerate this ongoing commercial effort with public-private partnerships to develop lunar infrastructure services jointly. As a result, NASA would benefit from these new, economical, commercial products and services to accomplish and accelerate its own lunar science and exploration missions to the Moon and beyond. In return, the commercial space industry would grow even faster and develop even more deep space capabilities. This symbiotic relationship between government and private industry would more than likely result in a very productive environment that would enable a new era of lunar industrialization.

\section{Concluding Remarks}

In summary, a public-private partnerships approach for developing an economical and sustainable lunar infrastructure was provided. Using a COTS-like acquisition model, this approach would establish partnership agreements between NASA and industry teams to share cost and risk in the development of lunar infrastructure capabilities for mutual benefit. As was discussed, this COTS-like acquisition model is based on the acquisition approach used in NASA's Commercial Orbital Transportation Services (COTS) program. This approach offered increased flexibility, innovativeness and dramatically lower costs, by as much as a factor of 10, than typical FARbased cost-plus contracts. In addition to much lower costs, the benefits to NASA would be new cis-lunar and lunar surface commercial products and services to accomplish and accelerate its lunar science and exploration missions. The benefits to industry would be shared technical expertise as well as shared development costs to help raise 
private capital, implement new business plans and lower risk to capture new lunar markets, such as lunar mining and lunar tourism, in a new frontier.

To further examine the merits and challenges of extending the NASA COTS model to cis-lunar space and the lunar surface, a Lunar COTS concept study was initiated. The goals of the Lunar COTS concept were to: 1) develop and demonstrate affordable and commercial cis-lunar and surface capabilities in partnership with industry; 2) incentivize industry to establish economical and sustainable lunar infrastructure services to support NASA missions and initiate lunar commerce; and 3) encourage creation of new space markets for economic growth and benefit. A phased-development implementation plan was also recommended to allow for incremental development and demonstration of capabilities. This plan was presented as a lower-risk approach since it would allow for several offramps throughout the development cycle and time for pause between phases to make sure its milestones and objectives are being met before proceeding to the next phase.

Phase 1 of this plan was discussed with its objectives focused on developing capabilities in partnership with industry to enable a commercial and economical lunar infrastructure system. The key elements of this infrastructure system included lunar lander, power station, communications, navigation, thermal control and surface mobility or rover systems. A reference lunar architecture consisting of all these elements was provided. The reference architecture's primary function was to evaluate performance, cost, and risk for each key element as well as examine technical and environmental challenges to be overcome to successfully implement an economical infrastructure system.

It was concluded that the greatest challenge for designing and operating hardware on the lunar surface is survival of the 14-day lunar night which can reach extremely cold temperatures of approximately $-258 \mathrm{deg} \mathrm{C}$ at the lunar poles. It was shown that few surface missions have successfully survived this lunar night, mostly using radioactive sources in RHUs or RTGs. To avoid the high costs and safety concerns of using such systems, a power station based solely on solar power and batteries was conceptually designed to survive multiple lunar nights and maintain an economical approach to infrastructure development. The primary function of this power station was to provide power generation and energy storage capabilities. This power station was also designed to recharge small rovers and other payloads while providing sufficient heat to maintain all critical systems within operating temperature limits through the 14-day lunar night. To meet these capabilities and functions, an analysis was performed on high TRL lithium ion batteries that were previously flown on the recent LADEE mission. As a result, it was shown that an estimated 24-36 battery modules would provide approximately 40-75 Watts of continuous power to run heaters sufficiently to survive a 14-day lunar night.

In addition, analyses of current and future launch vehicle capabilities showed that multiple landers (up to 4) including their payloads could be delivered to multiple lunar destinations on a single launch. This added capability would be a very cost-effective method for obtaining ground truth data at several sites in a single mission. In addition, it was shown that the power station can extend the mission life of rover systems from a few days nominally to several years with its recharging, thermal control and hibernation capabilities. Future plans to add a mobility system to the power station was also discussed. The purpose of this mobile power station would be to significantly increase the traverse distances of rover systems from a few hundred meters nominally to several hundred kilometers given that the power station with rovers can operate for 6-8 years.

Finally, a review of several commercial space companies was performed to evaluate the readiness level of these companies to participate in a potential Lunar COTS program. It was highlighted that several companies are presently investing their own resources to develop new, affordable capabilities to operate and provide services in cis-lunar space and the lunar surface. These companies are investing their own resources with the expectation that it will spark market demand for these new capabilities and as a result grow new space-based markets. Therefore, it is concluded that a COTS-like program, such as Lunar COTS, would serve to accelerate this ongoing effort by private industry to develop cis-lunar and lunar surface capabilities that would benefit both government and private industry. As a result of these public-private partnerships, NASA together with private industries would enable a new era of lunar industrialization.

\section{Acknowledgments}

The authors would like to acknowledge several members of the Lunar COTS study team for their contributions including: John Schreiner, Jessica Marquez, Alan Cassel, Jing Li and Rick Elphic. The authors would also like to recognize several members of the Ames Space Portal who also contributed to this work including Bruce Pittman, Lynn Harper, Ioana Cozmuta and Mark Newfield. Authors would also like to acknowledge the Ames management team for supporting this work including Gary Martin and Steve Zornetzer. 


\section{References}

1 "Treaty on Principles Governing the Activities of States in the Exploration and Use of Outer Space, including the Moon and Other Celestial Bodies," United Nations Office for Disarmament Affairs, Retrieved 2013-04-18.

2 Miller, C., Wilhite, A., Cheuvront, D. (et al), "Economic Assessment and Systems Analysis of an Evolvable Lunar Architecture that Leverages Commercial Space Capabilities and Public-Private-Partnerships," NexGen Space LLC under a grant from NASA, 2015. URL: http://science.ksc.nasa.gov/shuttle/nexgen/rlvhp.htm [cited July 2015].

3 Zuniga, A., Rasky, D., Pittman, R., Zapata, E., Lepsch, R., "Lunar COTS: An Economical and Sustainable Approach to Reaching Mars," AIAA Paper 2015-4408, AIAA Space 2015 Conference, Pasadena, CA, Sep 2015.

4 Zuniga, A., Turner, M., Rasky, D., Pittman, R., Zapata, E., "Kickstarting a New Era of Lunar Industrialization via Campaigns of Lunar COTS Missions," AIAA Paper 2016-5220, AIAA Space 2016 Conference, Long Beach, CA, Sep 2016.

5 "Commercial Orbital Transportation Services - A New Era in Spaceflight," National Aeronautics and Space Administration, NASA SP-2014-617.

6 NASA, "Falcon 9 Launch Vehicle NAFCOM Cost Estimates," August 2011, NASA Assoc. Deputy Administrator for Policy, http://www.nasa.gov/pdf/586023main_8-3-11_NAFCOM.pdf.

7 NASA Policy Directive 1051.1I, “Authority to Enter into Space Act Agreements,” Dec. 23, 2008.

${ }^{8}$ NASA Space Act Agreements Guide, NASA Advisory Implementing Instructions, NAII 1050-1C, Feb. $25,2013$.

9 NASA Funded Space Act Agreement Best Practices Guide, Human Exploration and Operations Mission Directorate, June 17,2015

${ }^{10}$ Schrunk, D., Sharpe, B., Cooper, B., Thangavelu, M., The Moon, Resources, Future Development, and Settlement, $2^{\text {nd }}$ edition, Springer-Praxis Publishing, Chichester, UK, 2008, pp. 3-11.

${ }^{11}$ Zak, Anatoly, "Russia's unmanned missions toward the Moon", RussianSpaceWeb, URL: http://www.russianspaceweb.com/spacecraft_planetary_lunar.html

12 NASA Office of Technology Utilization, "Surveyor Program Results," Compiled by Surveyor Program, Lunar and Planetary Programs Division, NASA SP-184, 1969.

${ }^{13}$ Freiman, Peter, Cmglee, License by Creative Commons Attribution-Share Alike 3.0 Unported license, URL: https://en.wikipedia.org/wiki/Moon_landing

${ }^{14}$ NASA Space Science Data Coordinated Archive, Surveyor 1, NSSDCA/COSPAR ID: 1966-045A, URL: https://nssdc.gsfc.nasa.gov/nmc/spacecraftDisplay.do?id=1966-045A.

${ }^{15}$ Launius, R.D., Johnston, A.K., Smithsonian Atlas of Space Exploration, Bunker Hill Publishing, Piermont, New Hampshire, 2009, pp. 100-113.

${ }^{16}$ Wikipedia source, URL: https://en.wikipedia.org/wiki/Yutu (rover), July 3, 2017.

${ }^{17}$ Reynolds, D. W., Apollo The Epic Journey to the Moon, Tehabi Books Inc., San Diego, CA, 2002.

${ }^{18}$ Hine, B., Spremo, S., Turner, M., "The Lunar Atmosphere and Dust Environment Explorer (LADEE) Mission," IEEE Conference, 2010.

${ }^{19}$ Elphic, R.C., Delory, G.T., Hine, B.P.et al, The Lunar Atmosphere and Dust Environment Explorer Mission (LADEE), Springer Science+Business Media, November 2014.

${ }^{20}$ Loucks, M., Carrico, J., Carrico, T., Deiterich, C., “A Comparison of Lunar Landing Trajectory Strategies Using Numerical Simulations," International Lunar Conference, Toronto, Canada, September 2005

${ }^{21}$ Carrico, J., Fletcher, E., "Software Architecture and Use of Satellite Tool Kit's Astrogator Module for Libration Point Orbit Missions," Libration Point Orbits And Applications: Proceedings of the Conference, Parador d'Aiguablava, Girona, Spain , June 2002. [Libration Point Orbits and Applications: Proceedings of the Conference Aiguablava, Spain 10 - 14 June 2002 ; J J Masdemont, Publisher: World Scientific Publishing Company | May 7th, 2003 | ISBN: 9789812383631, ISBN-10 9812383638]

${ }^{22}$ Loucks, M., Carrico, J., Concha, M., Craychee, T. “Trajectory Design Operations for the IBEX Mission,” Paper No. AAS 09-134, 19th AAS/AIAA Space Flight Mechanics Meeting, Savannah, Georgia, USA, February, 2009.

${ }^{23}$ Cooley, D. S., Galal K. F., Berry, K., Janes, L., Marr, G., Carrico, J., Ocampo, C.,"Mission design for the lunar CRater observation and Sensing Satellite (LCROSS)," Paper No. AIAA-2010-8386, AAS/AIAA Astrodynamics Specialist Conference, Toronto, Ontario, Canada, August 2010

${ }^{24}$ Moessner, D. P., and McAdams, J. V. , "The final two years: MESSENGER's trajectory from the third year in orbit through Mercury impact," 24th International Symposium on Space Flight Dynamics, http://issfd.org/, 18 pp., Laurel, MD, May 5-9, 2014.

${ }^{25}$ Kam, A., Plice, L., Galal, K., Hawkins, A., Policastri, L., Loucks, M., Carrico, J., et al, "LADEE Flight Dynamics: Overview of Mission Design and Operations," Paper No. AAS 15-212, 25th AAS / AIAA Space Flight Mechanics Meeting, Williamsburg, VA, January 11-15, 2015

${ }^{26}$ Folta, D., Demcak, S., Young, B. and Berry, K., "Transfer Trajectory Design for the Mars Atmosphere and Volatile Evolution (MAVEN) Mission," AAS/AIAA Space Flight Mechanics Meeting, AAS Paper 13-384, Feb. 2013

${ }^{27}$ Prussing and Conway, Orbital Mechanics, Oxford University Press, Inc. New York, New York, 1993.

${ }^{28}$ Sutton, George P., Rocket Propulsion Elements An Introduction to the Engineering of Rockets, fifth edition, John Wiley \& Sons, New York, 1986, pp. 96-127. 
${ }^{29}$ Berger, E., "SpaceX goes there-seeks government funds for deep space," Ars Technica online publication, URL: https://arstechnica.com/science/2017/07/spacex-urges-lawmakers-to-commercialize-deep-space-exploration/, July $13,2017$.

30 Berger, E., "Jeff Bezos saya NASA should return to the Moon, and he's ready to help," Ars Technica online publication, URL: https://arstechnica.com/science/2017/03/jeff-bezos-says-nasa-should-return-to-the-moonand-hes-ready-to-help/, March 3, 2017.

31 Astrobotic Press Release, “Astrobotic and United Launch Alliance Announce Mission to the Moon,” URL:

https://www.astrobotic.com/2017/7/26/astrobotic-and-united-launch-alliance-announce-mission-to-the-moon, July 26, 2017.

32 Sowers, G., Kutter, B., "Cislunar-1000: Transportation Supporting a Self-Sustaining Cislunar Space Economy,” AIAA Space 2016 Conference, Long Beach, CA, September 2016.

${ }^{33}$ Barr, J., "ACES Stage Concept: Higher Performance, New Capabilities, at a Lower Recurring Cost," AIAA Space 2015 Conference, Pasadena, CA, Sep 2015. 